$5^{\text {th }}$ INTERNATIONAL MULTIDISCIPLINARY

SCIENTIFIC CONFERENCE ON SOCIAL SCIENCES AND ARTS S G E M 2018

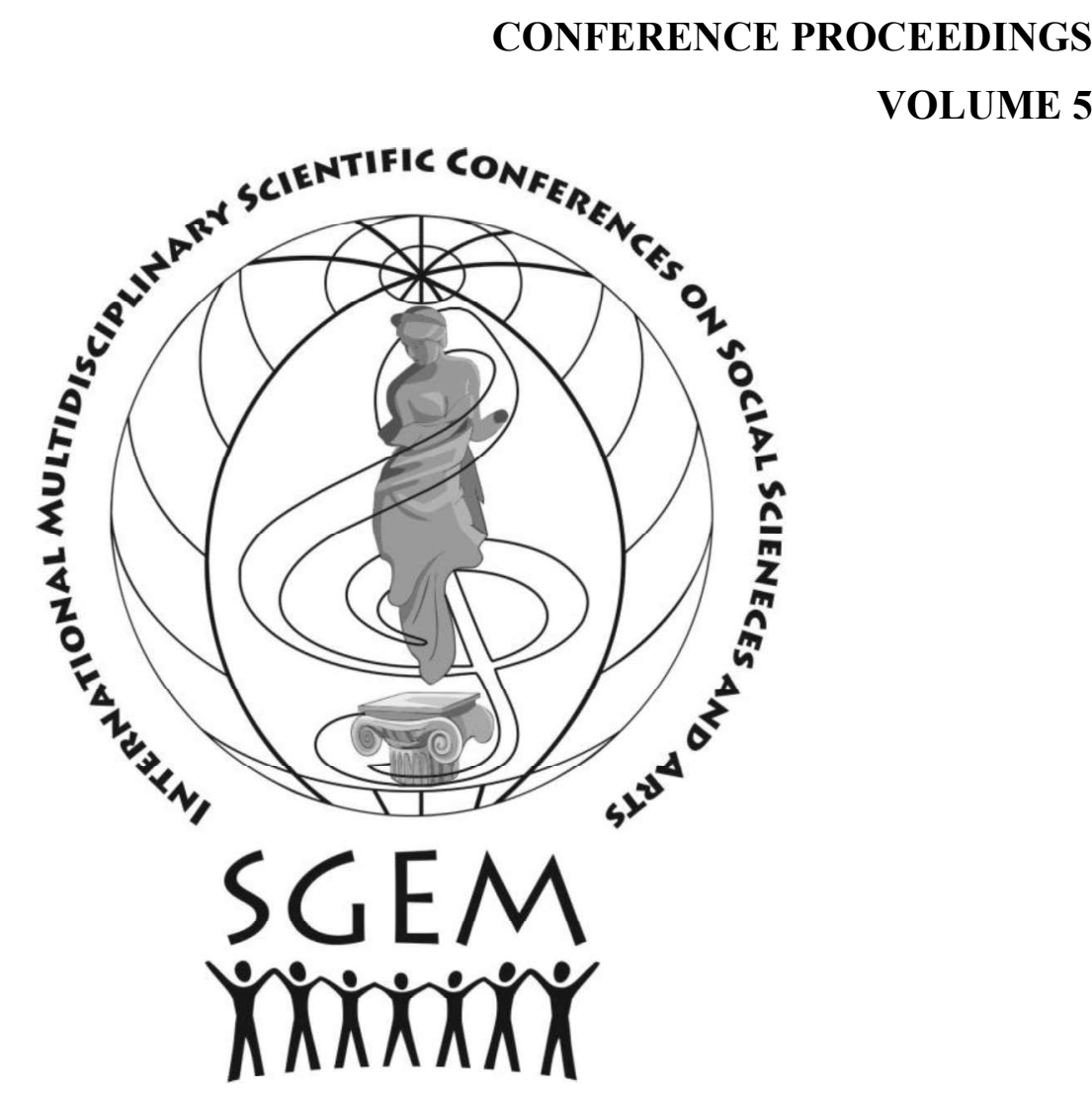

SCIENCE \& ARTS ISSUE 6.3

HISTORY OF ART, FINE ART, CONTEMPORARY ART, PERFORMING AND VISUAL ART, CULTURAL STUDIES, LITERATURE AND POETRY, ETHNOLOGY AND FOLKLORE Florence, Italy 


\section{DISCLAIMER}

This book contains abstracts and complete papers approved by the Conference Review Committee. Authors are responsible for the content and accuracy.

Opinions expressed may not necessarily reflect the position of the International Scientific Council of SGEM.

Information in the SGEM 2018 Conference Proceedings is subject to change without notice. No part of this book may be reproduced or transmitted in any form or by any means, electronic or mechanical, for any purpose, without the express written permission of the International Scientific Council of SGEM.

Copyright (C) SGEM2018

All Rights Reserved by the SGEM International Multidisciplinary Scientific Conference on SOCIAL SCIENCES and ARTS

Published by STEF92 Technology Ltd., 51 "Alexander Malinov" Blvd., 1712 Sofia, Bulgaria

Total print: 5000

ISBN 978-619-7408-69-0

ISSN 2367-5659

DOI: $10.5593 /$ sgemsocialF2018/6.3

SGEM INTERNATIONAL MULTIDISCIPLINARY SCIENTIFIC CONFERENCE ON SOCIAL SCIENCES AND ARTS

Secretariat Bureau

E-mail: borghese@sgemflorence.org

URL: www.sgemflorence.org 


\title{
HISTORIC URBAN SETTINGS, LED ILLUMINATION AND ITS IMPACT ON NIGHTTIME PERCEPTION, VISUAL APPEARANCE, AND CULTURAL HERITAGE IDENTITY
}

\author{
Asst. Prof. Dr. Karolina M. Zielinska-Dabkowska ${ }^{1}$ \\ Kyra Xavia ${ }^{2}$ \\ ${ }^{1}$ GUT LightLab, Faculty of Architecture/ Gdańsk University of Technology (GUT), Poland \\ ${ }^{2}$ Dunedin Dark Skies Group, New Zealand
}

\begin{abstract}
Many cities, towns and villages around the world have adopted new Lighting Emitting Diode (LED) technology in order to save energy, operational and maintenance costs. While energy-efficient, these light sources have a critical effect on the appearance of historic sites at night - and the technology has unique properties and numerous inherent drawbacks that present challenges to decision makers as well as inexperienced lighting professionals. This paper uses practice-based research, critical analysis of literature, interviews and observations to investigate the various issues involved with the application of LED lighting and proposes methods to address them. Lighting factors that impact nighttime perception and the visual appearance of cities as living structures are assessed, and European historic urban settings have been analyzed, including feedback from residents and tourists about their nighttime perception of the physical environment. The following research question is also answered, namely; if it's possible to work with the numerous drawbacks of existing LED technology to create and design quality spaces that support cultural heritage values after the sun sets? Additionally, photographic analysis is provided to demonstrate how to prevent the loss of specific ambience and associated cultural heritage inherited from past generations via an example of successful lighting in a real life, detailed case study of Najac village in France. This paper highlights the importance of best lighting practices, guidance from professional lighting designers, and lighting strategies for the future to ensure appropriate external illumination is achieved. Moreover, municipalities, heritage officers, and planners are introduced to effective, practical and responsible ways to adopt this new form of lighting. Although the term 'cultural heritage' has changed its meaning in recent decades, the authors propose that the nighttime ambience of historic urban settings be included in this definition. Not only does the appearance and atmosphere of a place at night establish a foundation of identity that interconnects people from different cultures, it is especially important for nighttime tourism. For this reason, cultural heritage should include physical elements of the built environment such as monuments, archaeological sites and historic urban settings that are inherited, maintained and preserved for the benefit of future generations by day and by night.
\end{abstract}

Keywords: LED illumination, cultural heritage, historic cities at night, heritage lighting, nocturnal urban settings, nighttime illumination 


\section{INTRODUCTION}

Today's work-focused lifestyle has meant many social activities now occur in the evenings, and as a result, historic cities, towns and even small villages are promoting awareness of their cultural heritage not only by daytime, but as special destinations to be enjoyed at night. To strengthen the perception of their significance nationally and internationally, regions are restoring key characteristics of historic cultural identity, visual hierarchies and meaning, as well as accentuating architectural and/or urban richness. There's also a strong incentive for historic tourist destinations to be seen as "greener", more environmentally friendly and sustainable as it's perceived positively by local residents and visitors, and demonstrates too, responsibility is being taken for the improved use and management of resources. For many municipalities, the move towards sustainability has involved the installation of energy efficient solid state lighting LEDs technology. Alas, a common misconception exists that LED technology provides only positive results, yet observation of streetlight retrofits around the world suggest otherwise. In fact, in the vast majority of cases, places of significance have been spoiled by the improper application of LED lighting. For instance; warm, soft and inviting ambience is lost, and in its stead is harsh, glary overlighting with strong contrast alongside unwanted shadows and pools of darkness. Perhaps one of the most simple examples that illustrates why expertise must be used when applying this technology, is that LED light sources cannot retrofit older style light sources on a unit per unit basis, because they have very different properties and characteristics. It's therefore, necessary to answer the question: can new LED lighting technology deliver the desired results to provide quality spaces that support cultural heritage values after the sun sets? This paper investigates what is required to protect historic sites and cultural heritage, and provides solutions to the challenges that exist. This research aims to establish a few elementary principles on how to properly illuminate cultural heritage urban settings at night. It's also hoped that these pressing matters are prioritized and given the due attention they deserve by architects, urban planners, heritage consultants and lighting professionals so that unfortunate outcomes can be avoided.

\section{MATERIALS AND METHODS}

The following set of research methods have been adopted to examine the previously mentioned issues and to answer related research questions; Practice-based research (this study is enriched by one of the authors' extensive professional experience in design offices that specialize in illumination of the built environment); Critical analysis of literature relevant to the research (to develop an overview of the existing body of work on the topic); Interviews with lighting designers and representatives of various European municipalities (with the objective of collecting relevant information to widen understanding of the topic's complexity). Furthermore, a method of Analysis has been applied to the gathered data, which was later Synthesised. The outcome should define useful existing practices essential for the successful implementation of nighttime illumination to preserve cultural heritage values. Lastly, a Graphical method has been introduced. (The research topic is supported by nighttime photographs to visually explain the problems highlighted and addressed in this paper). 


\section{CULTURAL HERITAGE DEFINITION - PROPOSAL FOR “AN UPGRADE”}

An accurate definition for cultural heritage in the context of our cities, towns and villages at night, is necessary because if this is not well established[1], understood and treated as valuable, it's likely this element of our nighttime urban environment will be deemed unimportant and ultimately lost. It's vital to act now to establish the conservation of historic nocturnal settings and to acknowledge the Italian Restoration Charter of 1972, which in Addendum D (Instructions for the protection of the Historical Urban Areas) states the following: "Restoration should not be limited to operations meant only to conserve the formal characters of single architectural works or single environments, but should include the substantial conservation of all the characteristics of the urban organism and all the elements that define it"[2]. It is our understanding that this pertains to the nighttime character of urban settings including physical elements such as appropriate style and form of luminaires that complement their historic surrounds, and also the quality of illumination provided by light sources.

\section{AN OVERVIEW OF VARIOUS ISSUES WITH THE APPLICATION OF LED LIGHTING}

All too often, the negative effects of poorly made decisions involving LED lighting are visible in our cities and towns - and they can incite protest by disgruntled residents, frustrated business operators and concerned citizens, as seen by comments expressed in social media that are then reported in the national and international press.

For instance: "At risk is the beauty of Rome, the charm of its old quarters, and respect for the city and its history. It's crazy that the unique character of old neighbourhoods in a Unesco-listed city has not been taken into consideration"'[3]. Illumination which disrespects the history and character, as well as the aesthetic value of spaces seems to be contentious: "LED lights for a historic piazza like this are just not right aesthetically.

The light they give off is too white, too harsh"[4]. The resulting fiasco in Rome meant some members of the professional lighting community sought to pinpoint responsibility for the visual aesthetic of historic cities, and questioned some of the decisions that were made: “[...] In Italy's historic cities it becomes a question of aesthetics. [...] But are we sure we want to put them [LED] in historic centers without taking into account aesthetic coherence? [...] Perhaps this is an issue for architects, because there are solutions "[5].

Municipalities will greatly gain when they work with those who protect cultural heritage, engage/consult with the public, clearly establish who is responsible for lighting, and seek the advice of lighting professionals who can guide them. Otherwise, they risk running into problems as shown by the following quote reported in the media: "the national authorities charged with protecting and preserving Italy's cultural heritage said that urban lighting had never fallen under their mandate"[6]. Not only is it embarrassing for decision makers, this situation is confusing to residents, as they do not know who to address regarding such urgent matters.

The above comments relate directly to the shortcomings of the LED light sources that were installed in Rome, which includes excess luminance, glare, non-uniform light distribution, inappropriate colour temperature, poor colour rendering index, as well as an absence of best lighting practices in general, resulting in overlighting, light clutter and light trespass - all of which suggest a lack of adequate expertise and sensitivity in the decisionmaking process involved with the implementation of the LED retrofit. 
The characteristics of LED light sources are briefly explained below to identify some of the various issues with the application of LED lighting and its impact on the visual appearance of the urban setting at night.

\section{Correlated Colour Temperature (CCT in Kelvin)}

$\mathrm{CCT}$ is an expression of the hue of the light emitted by a luminaire measured in degrees of Kelvin (K). Lower colour temperature light appears warmer to the human eye (more yellow), whereas higher colour temperature appears to be colder and is perceived as white or bluish white. (CCT is an inadequate metric because it only indicates how warm or cool a light source appears to the human eye. It provides no other information about the quality of light emitted by a light source). The reason warm lighting, below 3000 Kelvin, closer in light appearance to candle and firelight is suitable and apt for historic settings, is that this is similar to how they would have been lit and experienced by our ancestors before the advent and use of artificial lighting. Tourists want to be transported back to those times and lighting is one of the most effectively ways to create a mood, capture atmosphere and evoke a particular response.

A secondary factor to consider, is that we evolved with firelight so we have a strong emotional association of comfort, warmth and security - and in modern times, we gravitate to this relaxing, soothing and flattering light. Firelight is also soft and evenly dispersed so it's easy on the eye and complementary to appearances. For most of us, evenings serve as a time to relax, socialise and connect with others in an intimate way, and cosy lighting invites us to gather and linger in public places, for example: bar-lined streets in European historic city centres and towns. Ideally, LED lighting should be warm and aesthetically appealing when applied to areas where humans gather (it's also not as disruptive to human health and the environment as it emits less blue wavelengths of light). But LEDs that emit warmer coloured light are currently less energy-efficient. Until LED technology advances, choosing warm white lighting of $3000 \mathrm{~K}$ and below is a necessary concession for those municipalities who have prioritized energy, operational and maintenance savings. While cool white LEDs lighting (4000 Kelvin and above) adds a stark dramatic effect to buildings and landmarks at night, the light they produce typically has a peak in high intensity short blue wavelengths of light, the kind emitted by the sun, during daylight hours. The human eye registers this blue-rich light at night as white, and perceives it as especially harsh, clinical and unflattering.

The first European city to widely adopt cool white LED streetlights was Milan in Italy, and contrary to what was expected, the new lights created more light pollution which was recorded by the International Space Station. Images revealed that in 2015, the LED lit city centre was significantly brighter and whiter than the orange-hued sodium lit suburbs[7]. Despite this, many other Italian cities have installed cool white 4000K LED lighting, including Rome.

This change explains why so many residents expressed their outrage and displeasure at the retrofit in 2017. One municipal council member stated that: "Rome's historic centre now resembles a morgue. They have stripped away the welcoming atmosphere of Rome's most historic areas" [8]. Another resident complained that: "This LED light is really bright, really blue, it feels like a hospital light"[9]. "My neighbourhood is up in arms over the terrible LED street lighting that suddenly replaced the warm, yellow lamps that make Rome so romantic"'[10]. 
There was also concern from an individual who earns their living as a city tour guide: "There is a current program in Rome to take away all the incandescent light bulbs that provide the warm, diffuse and yellow glow that has come to define Rome at night and replace them with horrendous LEDs that cast a harsh, cold and strong light. [...] I can only compare it to a candle-lit dinner versus the frozen food aisle of your local grocery store"[11]. and from individuals employed in the restaurant business: "It's a big mistake. The old lights are characteristic of the historic centre. They create a romantic ambience, a memory of the era of La Dolce Vita of 50 years ago" [11].

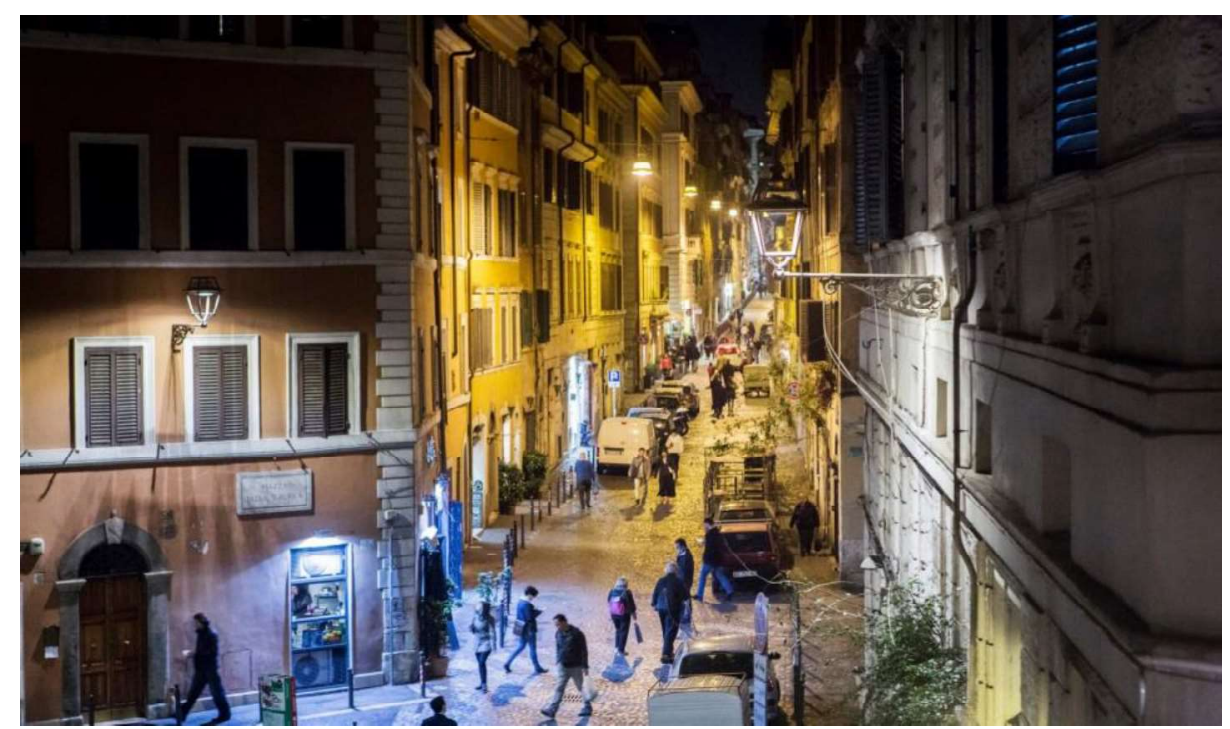

Figure 1: City of Rome/IT after the installation of new LED streetlights. (C) Gianni Cipriano/New York Times/Redux/eyevine

\section{Colour Rendering Index (CRI)}

CRI is an international system for the quantitative measurement of a white artificial light source for faithfully reproducing the colours of various objects in relation to an ideal or natural light source. It uses a scale of $0-100$. The higher the CRI number, the richer and more precise the colour appearance of an object, similar to how it would be viewed in daylight. The higher the CRI index of an LED light source, the more expensive it is as well. Unfortunately, this often means municipalities will purchase cheaper LEDs that produce inferior light. Also, continuous spectrum of visible light ensures optimal colour reproduction. Poor reproduction in colour results from choosing light sources that are too low in CRI which can have a negative effect on illumination projects, resulting in colour distortions (Figure 1).

The Italian Charter of Restoration of 1972 defines that: "No significant alternation must be made to the appearance of the material or the colour of surfaces" [12]. Therefore, chromatic authenticity of the materials used in the historic urban settings by day and night should be respected. This can be achieved by using white light LED sources with a CRI greater than 85 . 


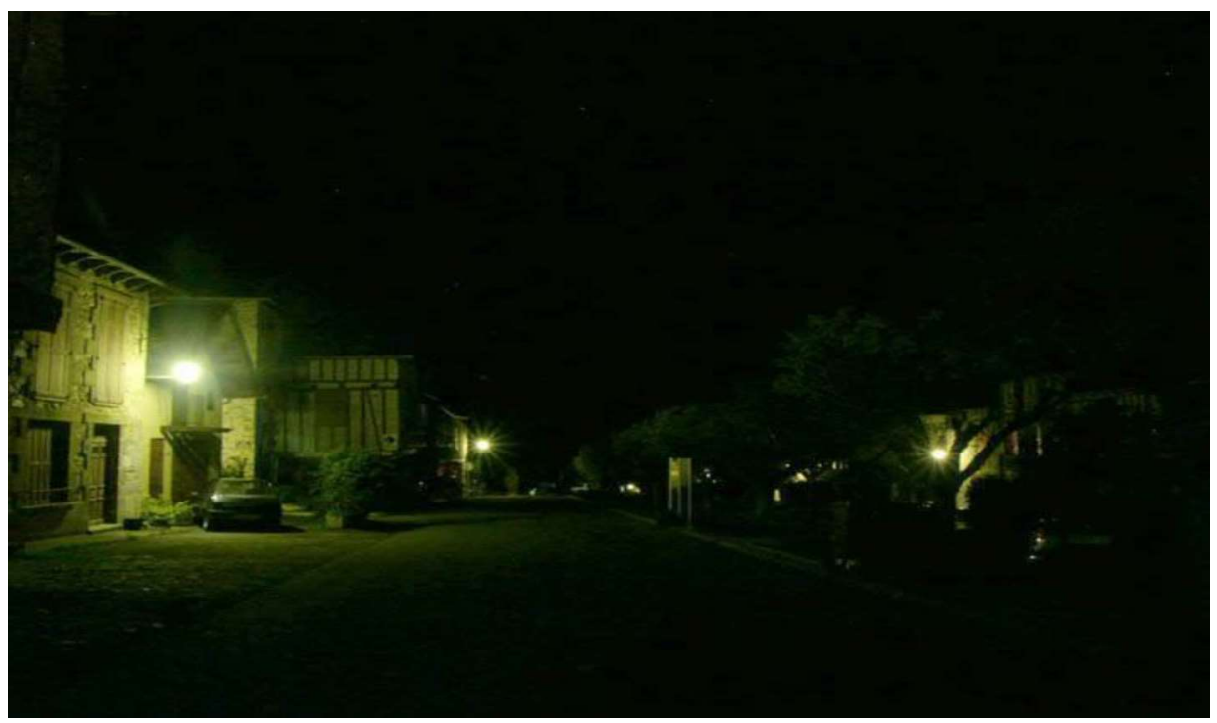

Figure 2: Village of Najac/FR before the installation of new LED streetlights. This photograph shows the old mercury-vapor lamps which produce white light with a bluish-green hue and a very low CRI. Such light is harsh and uncomplimentary to the surrounding architecture and various building materials and it is also unflattering to human skin tone. (C) Wonderfulight

\section{Luminous intensity distribution}

LED lighting is highly directional, unlike other forms of commonly used illumination such as incandescent and high intensity gas-discharge lighting, which is omni-directional, dispersing light evenly in all directions. This nonuniformity is observed as an area of intense brightness with a noticeable drop off that produces unsightly shadows. LEDs also emit excess luminance where too much light falls on the human eye. This not only causes glare, visual discomfort and unease as blue wavelengths of light scatter within the eyeball impairing visibility, the intensity of light also causes the pupil to contract which prevents dark adaption so one loses the ability to detect objects in the shadows. Furthermore, excess luminance causes extremes in contrast. This is illustrated in the complaint below by a municipal councillor of Rome: "Illumination is atmosphere. They are assassins of the beauty of Rome, of its history. [...] Look over there, at that 'Virgin and Child', with that ugly lamp above it, casting such a harsh outline. This used to produce a light with a golden halo, that soft and welcoming light that envelops you” [13].

\section{Colour}

The human eye can detect electromagnetic waves in the spectrum of $380-780 \mathrm{~nm}$. This visible light consists of seven colours: red, orange, yellow, green, blue and violet. Colour is observed when light of a specific wavelength mentioned above or combination thereof, reaches the retina of the eye. In the last few decades, it's become popular to apply coloured lighting (which often includes dynamic changes) to buildings, public spaces and even the historic centres of towns and cities. This development was first inspired by a form of night performances and entertainment already familiar to the 
French called "son et lumiere" which began to gain attention when the City of Lyon/FR established the light festival "Fete de Lumiere".

During the 1980s, Lyon was notorious for its gloomy depressing atmosphere, foggy weather, and dilapidated state - and the city needed to rebrand itself. In 1998, when the old town of Lyon was named a UNESCO World Heritage Site for its historical and architectural landmarks, the use of coloured light was one of the easiest, most affordable tools available to transform its buildings and public spaces into an aesthetic experience at night to attract visitors and market historical tourism [14]. Since then, the light festival of Lyon has become a major cultural event and is recognised around the world (Figure 3) and many other cities around the world have followed suit creating their own light festivals. While LED technology can provide an eye-catching rainbow palette of colours to choose from and all sorts of impressive dynamic effects, there's a problem. In the past, when urban settlements were first constructed, permanent lighting installations using vibrant colours weren't even a consideration. According to Article 6 of Venice Charter of 1964 for the Conservation and Restoration of Monuments and Sites (a set of guidelines, that provides an international framework for the conservation and restoration): " [...] Wherever the traditional setting exists, it must be kept. No new construction, demolition or modification which would alter the relations of mass and colour must be allowed" [15]. Today, the display of creative, coloured lighting of this type should be temporary and restricted to special events (as in case of Lyon's light festival), cultural celebrations and other festivities, due to the prolonged negative impact artificial lighting at night has on the environment.

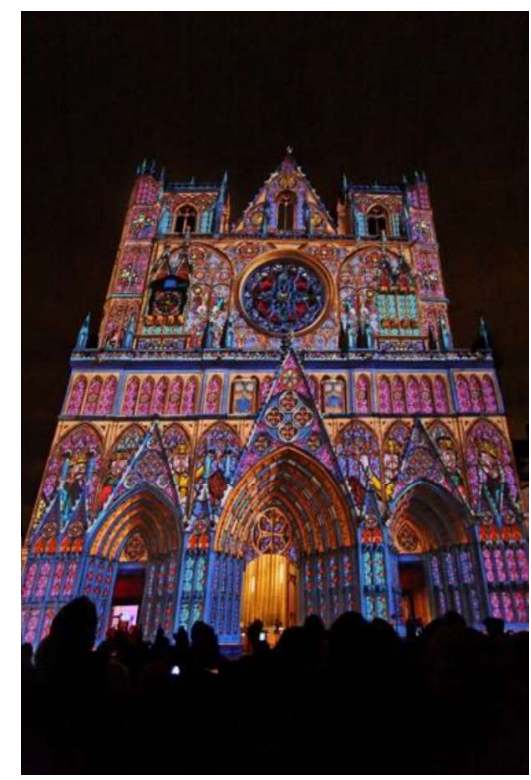

Figure 3: 3D mapping projection technique on the heritage building's façade of St. John 's Cathedral during the Fête des Lumières 2014 Lyon light festival (C) Pierre-Jean Durieu/Shutterstock.com.

\section{IMPACT OF LUMINAIRE STYLE}

When changing lighting in an historic setting, the style of luminaires will have a significant impact on the overall appearance of the streets, buildings, landmarks and the landscape they will illuminate, and they will also make a big difference to the visual 
appearance of the space during the daytime. In the majority of cases, such structures were built prior to the advent of electric lighting so luminaires need to be as complimentary as possible. Unfortunately, lighting designers have a limited range of luminaire styles to choose from and typically, they are 19th century Victorian-styled lanterns with four walls made of clear or diffused glass (Figure 4). (Most are also without shielding, resulting in light spill and light trespass into private properties, both of which increase light pollution.) Recently cities like Venice and Florence had their vintage-styled luminaires in historic part of the city retrofitted with LEDs. As mentioned previously, when replacing existing luminaires with an LED light source, the light distribution is different. LEDs in a vintage luminaire like this produce unwanted glare, excess luminance, and overlighting of the space. Another aspect of urban heritage that needs consideration, is the appropriate size and form of the luminaires. Their location on a building's facade or on a pole related to the mounting height and the spacing between the luminaires can also have a direct impact on the light distribution and uniformity (or lack of it) - and this will affect how well or poorly a space is illuminated. Additionally, the finish of the luminaire should blend in with the surrounding buildings and structures. Too often, unsuitable finished luminaires are placed on light coloured façades. Such designs should be avoided as they create visual chaos and disharmony.

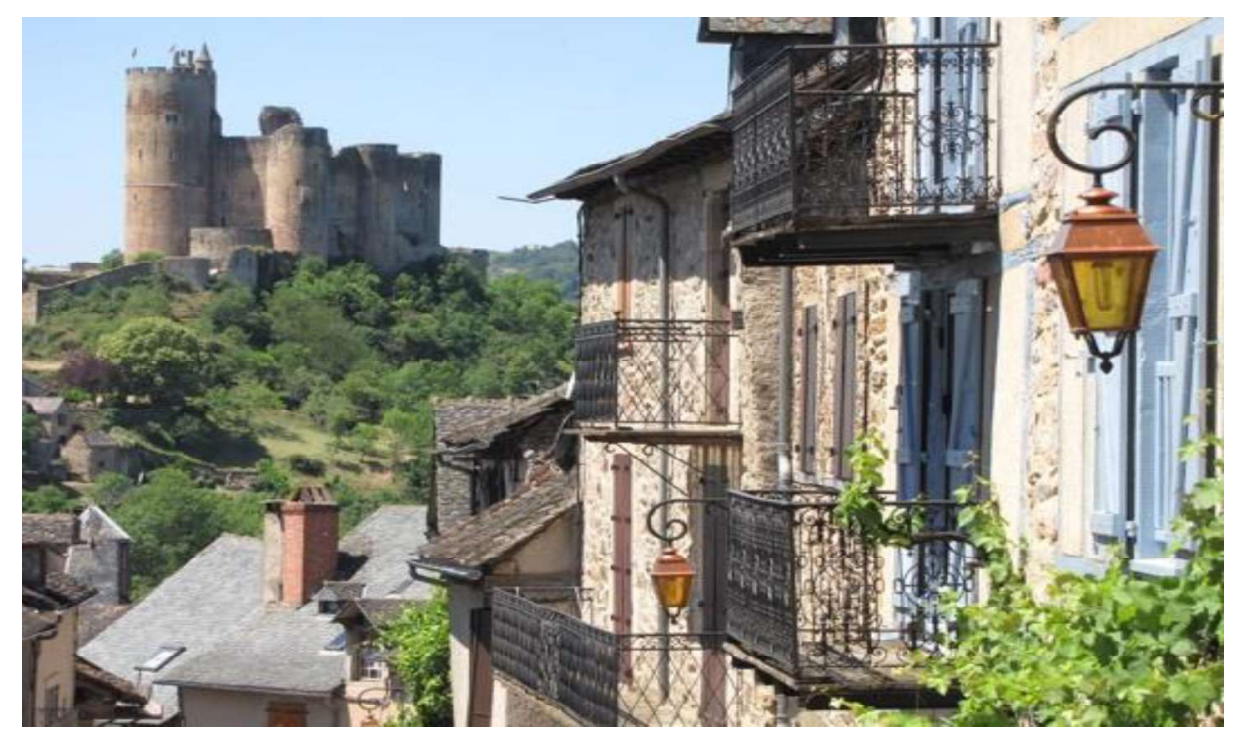

Figure 4: Village of Najac/FR before the new LED refurbishment with pseudo-historical style lanterns that are out of character for the medieval street and architecture of the town due to their Victorian style and orange glass. (C) Alain Colomb

\section{INDEPENDENT LIGHTING DESIGNER - ROLE AND RESPONSIBILITY}

In the professional lighting design community it is a well-known fact that artificial illumination is capable of changing the perception or meaning of a particular space or building. (This applies to all cultural heritage assets). Unfortunately, few decisionmakers in charge of outdoor illumination projects in urban settings fully appreciate the immense value of employing an independent professional lighting designer and the experience they bring to a project - and as a consequence, rarely invite them for 
collaboration. Lighting designers are the professionals involved in designing spaces at night to be illuminated with artificial lighting.

They conceptualize innovative solutions that integrate function, aesthetics, technical knowledge and artistic sensitivity to architectural, urban and landscape projects. They understand the many physical properties of light (colour temperature, colour rendering, its distribution, etc.), are versed in its physiological processes and the psychology of perception in humans, plus they're aware of the impact artificial illumination has on the environment, humans, flora and fauna, and they know how to mitigate or minimalize it. Lastly, when working in historic urban settings they possess knowledge of the history of arts, architecture (era, architectural styles etc.) which helps in the application and execution of their design. A notable distinction exists between the services provided by electrical engineers often employed by municipalities or energy companies, who light thoroughfares to meet the lighting classification of roads dictated by national and international traffic legislations - and lighting designers whose comprehensive approach differs, as explained above.

\section{DETAILED CASE STUDY: RESTAURATION OF MEDIEVAL VILLAGE OF NAJAC/FR}

Najac is a little village in the Aveyron department in southern France, renowned for its historic buildings of medieval character dated from 13th and 14th century and its urban typology. It is located in an historically important defensive position, built below the ruined royal fortress of Najac, above a bend in the Aveyron River. From a cultural heritage point of view, the entire urban setting is unique, built in the style known as a medieval perched village, nestled on a long rocky ridge, more than $2 \mathrm{~km}$ in length with buildings located on both sides. Surrounded by hilltops covered with green forests, Najac has a remarkable vista that spans the neighboring countryside. Entry to the village is through a narrow, protected entranceway in the historic defense. The village has narrow cobbled streets and arcaded passageways with houses built from local stone with characteristic slate tile roofs, and decorative features on the houses e.g. carvings, lintels etc. There is also a small Saint John village church. At one point, the road widens to create a local square with a highly decorated village fountain in the middle.

Many villages in this region began to fall into a state of disrepair by the end of the 18th century, and this trend continued into the 20th century, along with depopulation as residents moved to larger towns and cities in search of work. Najac was one such place to be affected, and in 2008, the population fell to just 752 .

To bring a new lease of life to the village, the community focused on historic tourism.

They spent three years in extensive consultation with an interdisciplinary team composed of an architect (Coco Architecture), landscape architect (Palimpeste), lighting designer (Wonderfulight) and engineer (AQR) to discuss the LED refurbishment and develop the concept. From the beginning, the services of a lighting designer were engaged as it was clear that specialized expertise was needed to deal with the complex task of illuminating the routes and buildings in a way that would match the vision of the project. Developing a new lighting design proposal for any settlement that was constructed centuries ago, can be both fascinating and challenging and it calls for respect for the history and character of urban form and architecture that was designed in a completely different era. 
Lighting designer Anne Bureau from Wonderfulight has supported the specific urban structure of the village at night by creatively illuminating the shape of its route and honouring it as a landmark. The goal was to create a meaningful quality space with atmosphere as this was much more than a simple beautification project. The monotony of a long route was turned into a journey of visual interest by applying specific luminous rhythm and using reflected light from wall mounted lanterns on vertical facades (Figure 5, Figure 6).

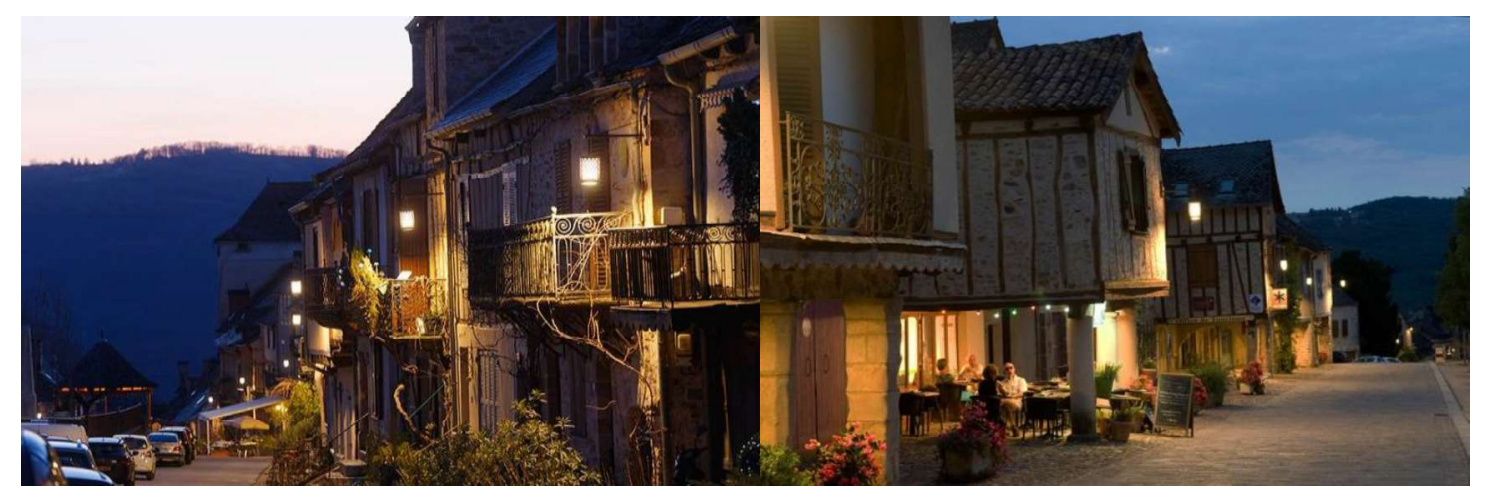

Figure 5: and Figure 6: The aesthetic design of the special lanterns complement this historical site, the architectural style of the building's facades, as well as the village's own identity, providing an attractive luminous rhythm along the pedestrian route (C) Patrice Nin/Comatelec; Jean-Marc Charles

A luminaire with medieval character was unavailable, so a special customized cylindrical lantern called "Najacoise" was designed that would be used throughout the village (either wall mounted or on the pole) to create visual cohesion (Figure 7). While the luminaire has a contemporary shape, it references very old medieval lanterns made of metal that originally had perforations to vent hot air.

The lighting designer drew upon the characteristic fishtail pattern of the slate roof from buildings in the area as inspiration. This pattern was cut out of metal to allow the light to shine out (Figure 8). Each Najacoise lantern with this historic motif now provides a visual connection to cultural heritage that is visible by day and night. Warm white lighting with a colour temperature of $3000 \mathrm{~K}$ was chosen with high colour rendering index so the local materials in the buildings are visible and able to be appreciated. Numerous versions of the lantern were designed and prototypes developed before final approval was made. 


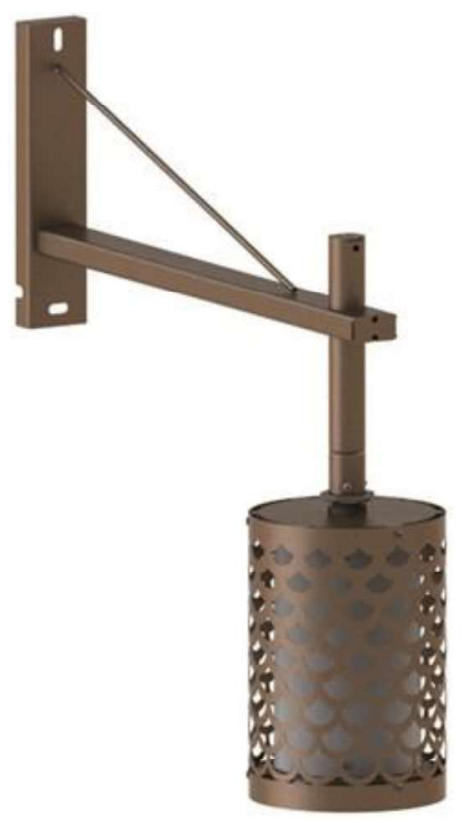

Figure 7: A customized cylindrical lantern called "Najacoise" with a bronze finish, especially designed to be used throughout the village to create visual cohesion. (This example is a wall mounted version) (C) Comatelec/Schreder
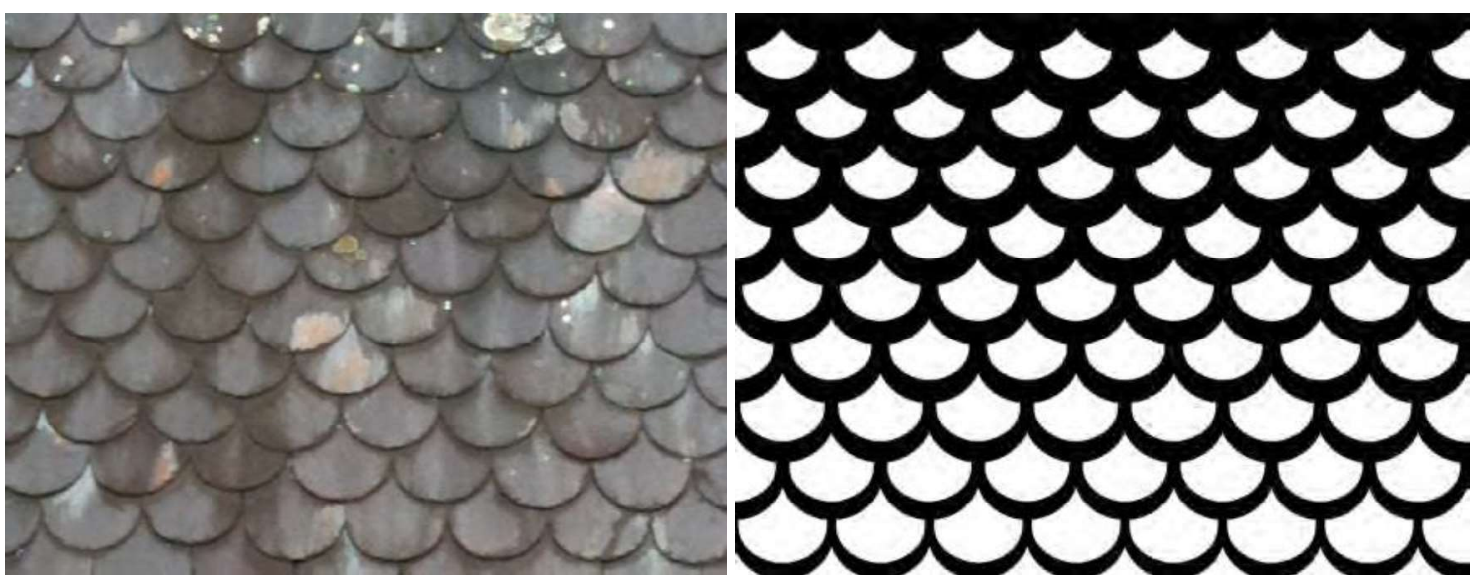

Figure 8: The characteristic shape of the slate roof fishtail pattern from the area (left), incorporated in the design of the "Najacoise" lantern serves four main purposes. The perforations allow light to shine from within the lantern and the fishtail motif embraces the village's history, it provides visual appeal and it also creates design cohesion throughout the village (right). C Wonderfulight

Arcaded passageways in the village were not illuminated with typical uplighting technique, but rather, luminaires were concealed from view, to gently illuminate the space with warm white downlighting. The village's Romanesque square with a decorative fountain received special accent lighting (Figure 9). Similarly, the wooden gazebo (where the music band is located during festivities etc.) was illuminated with concealed warm white LED lighting in the form of a luminiouse chandelier, visible only when one is in the space. 


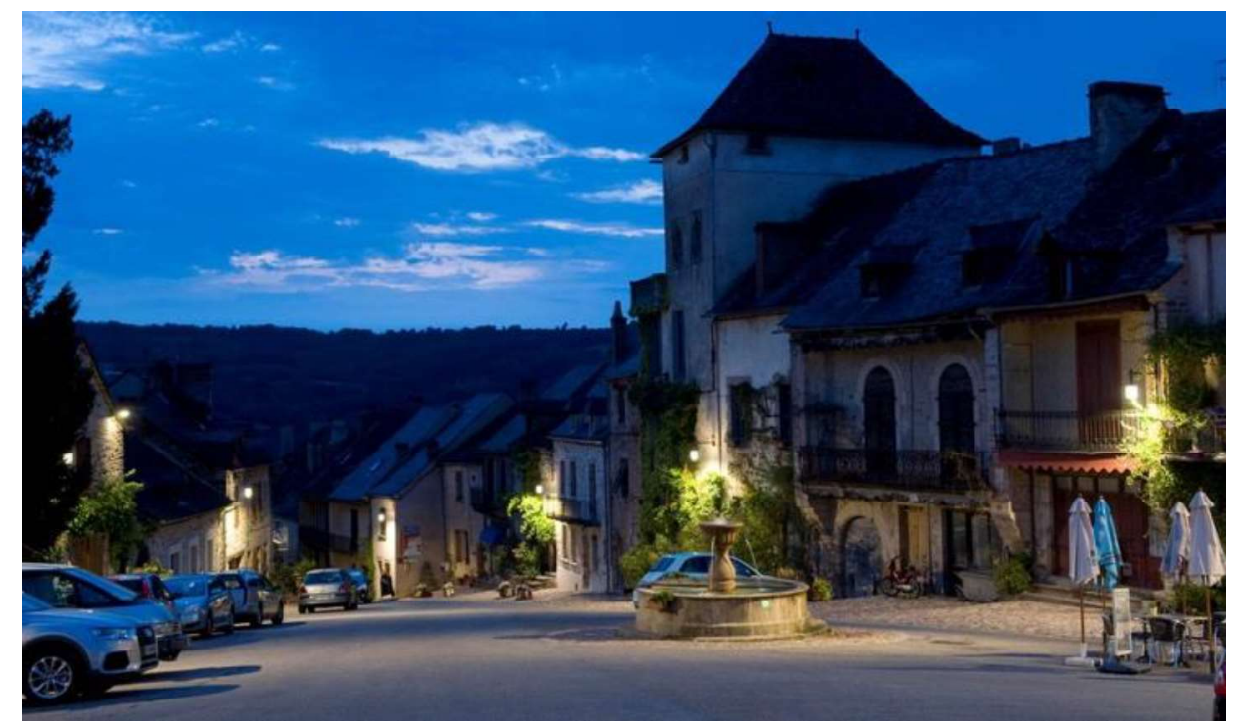

Figure 9: The village's Romanesque square and its decorative fountain that received special accent lighting. (C) Jean-Marc Charles

Lighting was also used to support wayfinding through the narrow medieval alley ways linking them to the larger outer route. Illumination was delivered by narrow beam projectors mounted at the top of the alley ways. In order to provide additional dimensions to the project, the lighting designer also highlighted existing decorative details of the buildings that are often hidden from view, by using gobos to project their images on dedicated building facades. The intention is to evoke curiosity in visitors about this graphical representation so they will go for a treasure hunt during the day to find them (Figure 10).

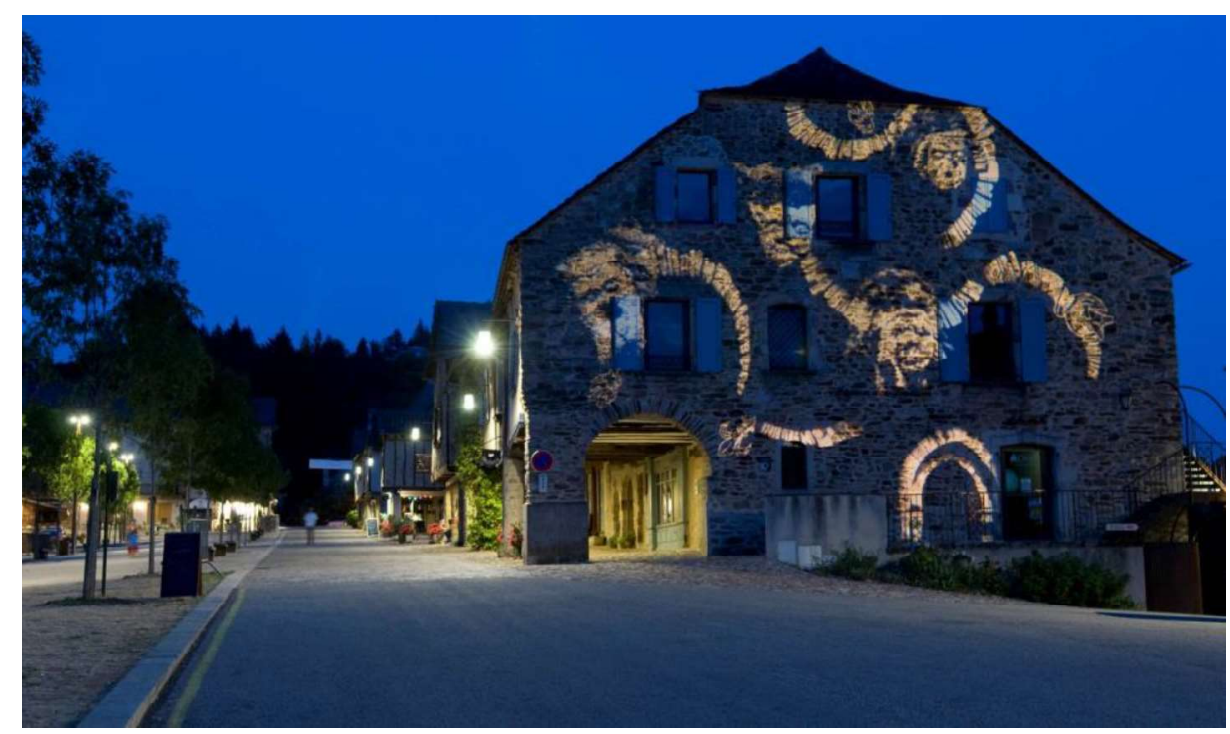

Figure 10: To highlight decorative details of the buildings that are often hidden from the view, gobos are used to project large images of them on dedicated building façades. (C) Jean-Marc Charles 
Najac municipality's goal was to ensure existing exterior lighting was replaced with lighting that would significantly enhance the streetscape and nighttime environment while providing a safe, effective and sustainable urban place for the entire community. Scene setting is also integrated into the lighting system so illumination is flexible and can be adjusted according to the day, week, and seasons, and factor in the attendance of people during festive or tourist periods.

Due to the low light levels (10 to 15 lux with no dimming required) good energy efficiency is achieved (the current LEDs consume only $1 / 4$ of the former wattage per luminaire). Najac's street lighting is in continual operation every day between the sunset and sunrise. For special occasions (night markets) additional lighting can be switched on when required.

It is worth mentioning, that before the implementation of the new lighting strategy, Najac received the official title of the most beautiful French village, from the independent association Les Plus Beaux Villages de France. This designation recognises the value of the village's visual appearance and its appealing scenic atmosphere and its promotion as a tourist destination with a rich cultural heritage. The newly completed, improved lighting of Najac plays a vital role in enriching the village by nighttime, allowing picturesque walks and evenings spent enjoying dining and socialising al fresco.

\section{CONCLUSION}

Nighttime illumination has a significant impact on the visual appearance of an urban space and the objects, buildings, artefacts, landscape etc. within it, and this greatly influences the perception of users (residents, visitors, tourists). For this reason, it's crucial for cities dependant on historical tourism to have lighting that enhances the cultural heritage identity of its urban settings. Lighting should also enhance the experience of the space so inhabitants are invited to enjoy and appreciate it.

As our research and case study indicates, nighttime illumination for an urban setting is a complex undertaking, and while there are far too many examples today, of poorly executed LED projects - with the right expertise, approach and methods, enhanced lighting can become the norm, not the exception. Indeed, this is what all cities, towns and villages should strive for. It's important to note, that when preserving the nighttime character of historic sites, any new lighting must improve upon the older style lighting that it replaces.

In order to implement appropriate LED illumination in historic settings, municipalities, heritage officers, and planners need to be introduced to, and also understand effective, practical and responsible ways to adopt this new form of lighting, as well as the effects they might have on their projects. To assist this process, the following recommendations have been proposed:

- Urban built environments have been designed for humans so their illumination should support nighttime visual requirements in order to perceive and navigate the space well.

- Minimize overlighting and discomfort glare because they contribute to environmental light pollution and are a safety hazard. (Bright lighting and glare reduces visibility of the surrounds and hinders proper navigation of a space). 
- Use LEDs with an appropriate colour temperature to create mood, capture atmosphere and evoke a particular visual and emotional response.

- Use appropriate colour rendering index of LED light source to compliment surrounding architecture, building materials and the colours of these structures.

- Avoid excessive brightness and extremes in lighting contrast.

- Create scene settings based on the time of the day, week, seasons etc.

- Allow for dimming features to change the light levels according to scene setting to reduce light pollution and minimize its impact on the environment.

- Coloured lighting in permanent installations should be discouraged.

- Install appropriate styled lanterns in keeping with the character of the space.

- The services of professional independent lighting designers is encouraged, as they have the necessary knowledge about historical context and the skills to design projects that best highlight the unique character of a place in an appropriate and sensitive way, whilst providing visual harmony.

Finally, it is recommended that physical elements of the built environment such as monuments, archaeological sites and historic urban settings that are inherited, maintained and preserved for the benefit of future generations by night, be included into the definition of cultural heritage. This will allow cities, towns and villages to hold onto the rich visual cultural heritage and identity that they have during the day, into the night as well. It is anticipated that this work will have a positive impact on academia, as it introduces practice-based research as a new valuable approach. As the case study included in this paper shows, the development of a universal lighting concept to preserve, protect and enhance cultural buildings and sites in urban settings using LED technology is not only possible, it offers many benefits.

\section{ACKNOWLEDGEMENTS}

We would like to thank French lighting designer Anne Bureau of Wonderfulight for sharing her urban lighting project for the little village of Najac/FR presented in this paper to support our research.

\section{REFERENCES}

[1] UNESCO, Protecting Our Heritage and Fostering Creativity. The Convention concerning the Protection of World Cultural and Natural Heritage, Addendum D, Oct. 17 - Nov. 21, 1972. Paris, France. [Online] Available: http://www.unesco.org/ new/en/ culture/. [Accessed: Oct. 7, 2018].

[2] Ministry of Education, Italian Restoration Charters of 1972, Memorandum no. 117, p.10, Apr. 6, 1972. [Online]. Available: http://sangeministudies.info/italianrestoration-chart-of-72-rev-08 [Accessed: Oct. 7, 2018].

[3] Squires, N., "Romance of Rome under assault from ugly LED lighting, campaigners say", The Telegraph, Apr. 2, 2017. [Online]. Available: https://www.telegraph.co.uk /news/2017/04/02/romance-rome-assault-ugly-ledlighting-campaigners-say/ [Accessed: Oct. 7, 2018]. 
[4] Ibid 3.

[5] Povoledo, E., "Streetlight Fight in Rome: Golden Glow vs. Harsh LED", The New York Times, Mar. 27, 2017. [Online]. Available: https://

www.nytimes.com/2017/03/27/world/europe/rome-streetlights-led-lights.html [Accessed: Oct. 7, 2018].

[6] Ibid 5.

[7] Zielinska-Dabkowska, K.M., "Make lighting healthier", Nature, vol. 553 /no. 7688, pp. 274-276, 2018. [Online]. Available: https:/www.nature.com/articles/ d41586-018-00568-7 [Accessed: Oct. 7, 2018].

[8] Ibid 3.

[9] Gavin, J., "Rome turns to cost-saving LED lighting but some residents unhappy", Reuters. Apr. 5, 2017. [Online]. Available: https:/www.reuters.com/article/usitaly-lights-idUSKBN1771IC [Accessed: Oct. 7, 2018].

[10] Ibid 3.

[11] Molony, R.,"Romans label LED lights as 'assassins'of city's beauty", Luxreview. Apr. 4, 2017. [Online]. Available: http://luxreview.com/article/2017/04/romanslabel-new-led-lights-as-assassins-of-city-s-beauty [Accessed: Oct. 7, 2018].

[12] Ginesi, A., The illumination of monuments and other cultural assets: towards a theory. iGuzzini Study and Research Centre. Rozzano (Milano): Editoriale Domus,

p 116, 2002.

[13] Ibid 3.

[14] Zielinska - Dabkowska, K.M., Night in a big city. Light festivals as a creative medium used at night and their impact on the authority, significance and prestige of a city [in] The Role of Cultural Institutions and Events in Marketing of Cities and Region, Domański, T. (Ed.). Lodz: Lodz University Press, pp 69-74, 2014.

[15] ICOMOS, International Charter for the Conservation and Restoration of Monuments and Sites (The Venice Charter of 1964), Art.6. 2nd International Congress of Architects and Technicians of Historic Monuments. Venice, Italy, May 25 - 31, 1964. [Online]. Available: https://www.icomos.org/en/ participer/179-articles-en-francais/ressources/charters-and-standards/157-thevenice-charter [Accessed: Oct. 7, 2018]. 